\title{
Aspects regarding the integration of children with special educational needs through participation in physical education
}

Authors' Contribution: A Study Design

B Data Collection

C Statistical Analysis

D Data Interpretation

E Manuscript Preparation

F Literature Search

G Funds Collection

\author{
Dana loana Cristea ${ }^{\mathrm{ABCD} F}$, lonuț Moțoc ${ }^{\mathrm{BCDF}}$, Anca-Cristina Pop ${ }^{\mathrm{BCE}}$ \\ Department of Physical Education, Sport and Physical Therapy, University of Oradea, \\ Romania
}

abstract

Background: Special education offers ways to the best capitalization of the possibilities that children in difficulty may have. These children, and especially those with mental and behavioral disabilities, need additional, competent supervision from specialists. Children and young people with special needs (SEN) are included in social (re)integration programs whose objectives can also be achieved through sport activities.

Material and methods:

In the high school where the research was conducted, during the observational practice, students with mild special educational needs are integrated into mainstream education and participate in physical activities.

Results: $70.40 \%$ of the secondary school students and $71.10 \%$ of the primary school students agree with the inclusion of students with SEN in teams with the other students in the physical education class, and $16.60 \%$ and $14.50 \%$, respectively, consider that they should be relieved of effort, while $13 \%$ and $14.50 \%$ want to practice separate classes.

Conclusions: The results of the study show that students with disabilities can be integrated through physical education activities, being accepted and encouraged by their peers. However, the lack of specialized teachers raises certain barriers in achieving the integration of people with SEN.

Key words: special needs, physical education, inclusion.

\section{article details}

Article statistics: Word count: 2,871; Tables: 0; Figures: 8; References: 24

Received: June 2020; Accepted: August 2020; Published: November 2020

Full-text PDF: http://www.balticsportscience.com

Copyright @ Gdansk University of Physical Education and Sport, Poland

Indexation: Celdes, Clarivate Analytics Emerging Sources Citation Index (ESCI), CNKI Scholar (China National Knowledge Infrastructure), CNPIEC, De Gruyter - IBR (International Bibliography of Reviews of Scholarly Literature in the Humanities and Social Sciences), De Gruyter - IBZ (International Bibliography of Periodical Literature in the Humanities and Social Sciences), DOAJ, EBSCO - Central \& Eastern European Academic Source, EBSCO - SPORTDiscus, EBSCO Discovery Service, Google Scholar, Index Copernicus, J-Gate, Naviga (Softweco, Primo Central (ExLibris), ProQuest - Family Health, ProQuest - Health \& Medical Complete, ProQuest - Illustrata: Health Sciences, ProQuest - Nursing \& Allied Health Source, Summon (Serials Solutions/ProQuest, TDOne (TDNet), Ulrich's Periodicals Directory/ulrichsweb, WorldCat (OCLC)

Funding: This research received no specific grant from any funding agency in the public, commercial, or not-for-profit sectors.

Conflict of interests: Authors have declared that no competing interest exists.

Dana Ioana Cristea, 1 University St., 410087 Oradea, Romania, e-mail: danacristea07@yahoo.com

This is an open access article distributed under the terms of the Creative Commons Attribution-Non-Commercial-NoDerivatives 4.0 International (https://creativecommons.org/licenses/by-nc-nd/4.0/), which permits use, distribution and reproduction in any medium, provided the original work is properly cited, the use is non-commercial and is otherwise in compliance with the license. 


\section{INTRODUCTION}

Marked by the modern technology, by the virtual world that chained him in the closed space of the workplace or home, the contemporary man has moved away from nature and from sports arenas $[1,2,3]$. The fact that today many children "practice" different sports on the computer, while being "exempted" by their excessively protective parents from physical education classes held in school is a real and extremely dangerous social phenomenon [4]. This reality is an alarm signal for all the factors involved in the formation process of the young generation [5]. Education is the basic pillar of human becoming/ development. Special education offers ways to the best capitalization of the possibilities that children in difficulty may have. These children, and especially those with mental and behavioral disabilities, need additional, competent supervision and additional efforts on the part of educators, to give them maximum assistance in order to perform at the highest possible levels in all activities that can be approached by them [6]. The child with mental deficiency has difficulties in social integration, professionalization, reducing the ways of spending free time [7]. Improving his physical condition would lead to the transformation of the disabled child into an independent person or reoriented towards other living conditions, implicitly avoiding the occurrence of obesity, which is common in children with disabilities [8,9]. Specialists in the field state that the psychomotor skills of children with intellectual disabilities can be improved by specific techniques, implicitly by an increased attention from the family [10-12]. Children and young people with special needs (SEN) are included in social reintegration programs whose objectives can also be achieved through sports activities.

Adapted sport is a branch of sport that uses motor/motive/movement structures, specific rules, material and organizational conditions modified and appropriate to the needs/ requirements of different types of disabilities [13].

From the point of view of physical activities, these groups are united by two factors: 1. the difficulty in participating in physical activities through sports clubs and associations; 2. self-motivating component of physical activity - of a pronounced importance for life.

In order to reach the final goal - to increase the quality of life through adapted physical activities, the following is aimed at: an increase in physical capacity, an increase in fitness, an increase in self-confidence, an increase in pleasure from physical activity. Through these activities, people must find a place where they are understood and respected, feel safe while the motor, sensory and affective components are stimulated / activated, verbal and nonverbal communication leads to specific adaptations of the meanings of communication, motor and intellectual abilities are improved, activities complete socialization and addictions are reduced. The role of the application of adapted physical activities aims either at the involvement in the most diversified social actions or at the provision of assistance to social groups in order to integrate those with difficulties in social adaptation.

In accordance with the Convention on the Rights of the Child, the Government of Romania adopted Decision no. 972/1995, approving the National Action Plan in favor of the child. Within this plan, point $\mathrm{V}$ specifies:

- adapting the content of special education, depending on the disability and the special educational requirements/needs of the children;

- access of children with disabilities, depending on their potential, to the structures and programs of regular education.

To support children with disabilities, action will be taken in order to:

- provide unrestricted access of children with mild disabilities to general education; 
ensure that the creation of new auxiliary schools is an exception, and the integration of groups and special classes in ordinary schools is preferable;

- compile a unitary methodology for multidisciplinary evaluation of children with different disabilities [14].

As we can see, the existing legislation does not help the social integration of people with disabilities, but makes them dependent on social assistance. Thus, home education for the immovable persons is non-existent because it is expensive. People with disabilities benefit from free public transport, but the means of transport are not accessible for people with severe physical disabilities. Medical assistance, treatments and technical aids are free only in written documents. There exist jobs in protected units but in a very small number, and sometimes they are not properly adapted to the situation of the disabled person. Streets, sidewalks and public buildings continue to be inaccessible, although there are regulations in this regard.

Some authors believe that the culture of physical education should be changed by creating an inclusive environment, and teachers should acquire various skills to work with people with disabilities $[15,16]$, otherwise the inclusion process could suffer as stated $[17,18]$. Regarding the aspect of inclusion, either in regular classes or in special classes, some authors stated that they did not identify differences, but they emphasized the aspect related to the type of deficiency [19]. There are also authors who obtained negative results in terms of inclusion in physical education classes, due to the social context (family, colleagues, teachers) that facilitated or inhibited the inclusion process [20, 21]. However, there are studies that highlight a major change in legislation in favor of people with disabilities, which, of course, contributed to the inclusion process [22-24].

\section{Assumption}

The research aims at highlighting whether the integration of children with special educational needs (SEN) in mainstream education is facilitated by physical activities.

\section{Research objectives}

The development of sports skills for different categories of children with SEN involves:

- gaining experience in sports competitions,

- social inclusion,

- participation in sports activities,

- education of young people in mainstream schools regarding people with disabilities,

- involvement of the families of children with SEN in their integration in sports activities,

- personal development of children with SEN.

\section{MATERIAL AND METHODS}

In the high school where the research was conducted during the observational practice, students with mild special educational needs are integrated into mainstream education and participate in physical activities. In good development of the activities, collaboration between school, family, and society has an important role. In order to know better the children with SEN who are integrated in mainstream education, in the school where the research was done, we documented discussions about individual cases with the school's psychologist and with the teachers, with the class masters of the classes in which the children were integrated. We had at our disposal the personal files of these children, in which we found out the educational route of each one, as follows: out of the total number of 7 children with SEN in primary school, 2 come from Roma families with a precarious family situation (5-7 children; unemployed parents) and with intellectual disabilities, which contributes to their difficult integration in the collective of their class. 2 children come 
from families with a very good material and educational situation; one with a locomotor disability, and the other one with an intellectual disability caused by a brain disease. 3 children are in family placement; they have a special environment within the families in which they live, being well taken care of, educated, accepted by all the members of their families; they have both locomotor and intellectual disabilities.

In secondary school we identified 7 children with SEN integrated in mainstream education, as follows: 4 come from Roma families that have a poor family environment, a large number of family members, parents who do not have a job, living on social assistance, and the children have intellectual disabilities - the fact that makes their integration very difficult in the class; 3 students are in family placement where they have very good living conditions in the families, are accepted by all the family members, and are supported in their instructive educational activity. Of these, 2 have an intellectual disability and one has a locomotor disability.

In order to ensure the informative base of the research, the following stages were taken into account: query of bibliography regarding the chosen topic, its analysis and interpretation; interactive communication with students from primary and secondary school classes in which children with SEN are integrated; the study of the curricular documents, methodical books of reference, guides. The place of the research was the gym and the outdoor field as well as the classrooms, watching the behavior of the students involved in other extracurricular physical activities that could provide data related to the research. In order to verify whether or not the study hypothesis/assumption is confirmed, we applied a questionnaire designed in collaboration with the school psychologist.

\section{Conducting the study}

The sample to which we applied the research questionnaire, includes students from 3rd and 4 th grades from the primary cycle and students from 5th , 6th ,7th ,8th grades from the secondary cycle. Before applying the questionnaire, with the support of the psychologist from the school, we met the students with SEN from the classes mentioned above, the type of disability that each had and their way of manifestation in curricular and extracurricular physical activities. The questionnaire includes 13 grid-type questions with several answer options (3-4), depending on the proposed objective.

In order to better understand these children's motor skills and abilities, we attended physical education classes/hours in the above mentioned classes. During the physical education classes, the observations necessary for the proper development of the research were noted. The observation period and the accumulation of notes extended during February and March of the school year 2018-2019, and the sample of children with disabilities consisted of 14 children, of which 7 children in the primary classes, and 7 children in the lower secondary cycle. We prepared 170 questionnaires, which were distributed to 62 students aged 9-10, and 108 questionnaires applied to students aged 11-14. The students were explained the content of the questionnaires, its purpose and the objectives pursued after completing the questionnaires. Before applying the questionnaire, students and parents were informed about the purpose of this study and the teachers of the classes supported us in the smooth running of the activity. In order not to influence emotionally the students participating in the questionnaire, they were supervised by their own teachers.

\section{RESULTS}

After studying and analyzing the questionnaires, they were processed, and the final results were correlated with the permanent observation of the behavior during physical education classes. $48 \%$ of secondary school students stated that they could participate in physical 
education classes just like them (category B). 26\% stated that they needed support to be able to exercise (category $\mathrm{C}$ ). An equal percentage of $13 \%$ each chose the answers that they should be exempted or they should not participate (category A and D) (Figure 1). In this question, primary school students stated that students with SEN could participate just like them in physical education class (55\%) (category B). 19\% said they needed support to exercise (category C). An equal percentage of 13\% stated that they should be exempted or should not participate (category A and D) (Figure 2).

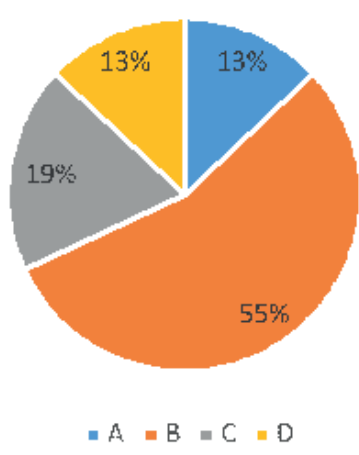

Fig. 1. Primary school cycle

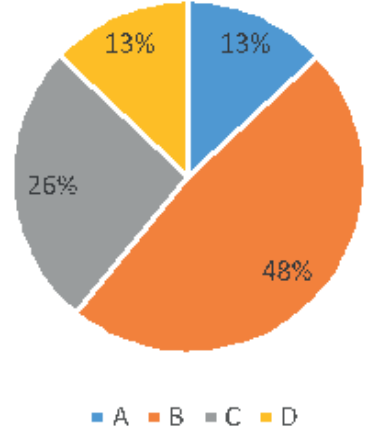

Fig. 2. Secondary school cycle

The secondary school students expressed their opinion regarding the acceptance of a teammate with SEN, as follows: $44 \%$ agree to have a teammate with SEN (category A); $38 \%$ do not know (category C), and 18\% do not agree to have a child with SEN as a teammate (category B) (Figure 3). In question number 5, 65.5\% of primary school students agree to have a child with SEN as a teammate (category A); $24 \%$ of the students do not know (category C); and 11\% of students do not want to have a child with SEN in the team (category B) (Figure 4).

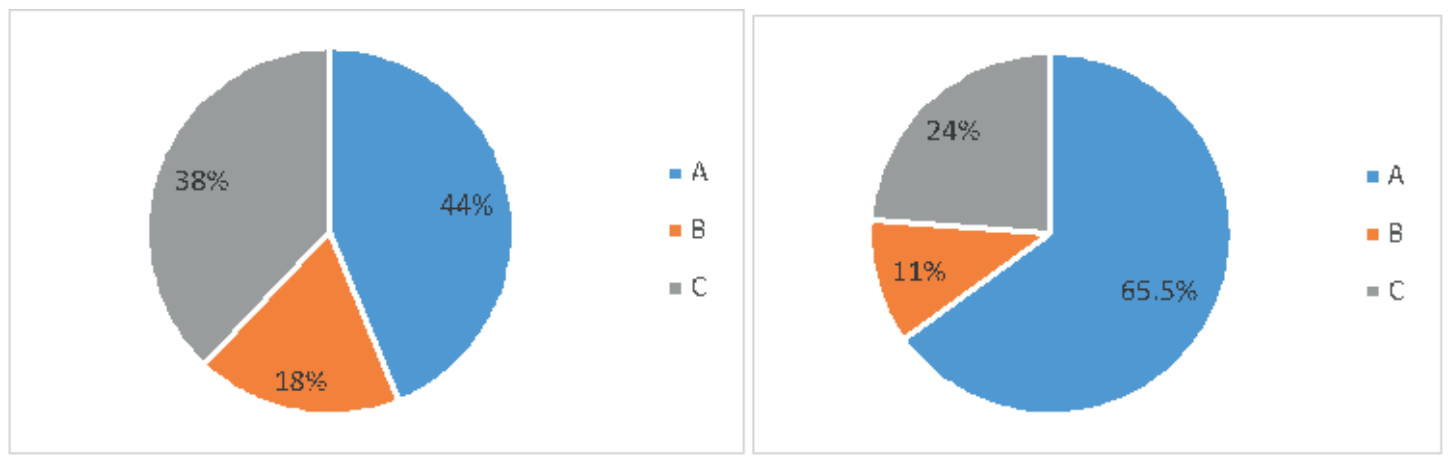

$54 \%$ of secondary school students answered question number 6 that during physical education classes, students with SEN participate in the same way as other children (category A). 31\% stated that they sit on the bench (category B), and 15\% stated that they were marginalized by others (category C) (Figure 5). Primary school students have the same opinions but in different percentages: $74 \%$ chose the first option (category A), 15\% the second option (category B), 11\% the third option (category C) (Figure 6). 


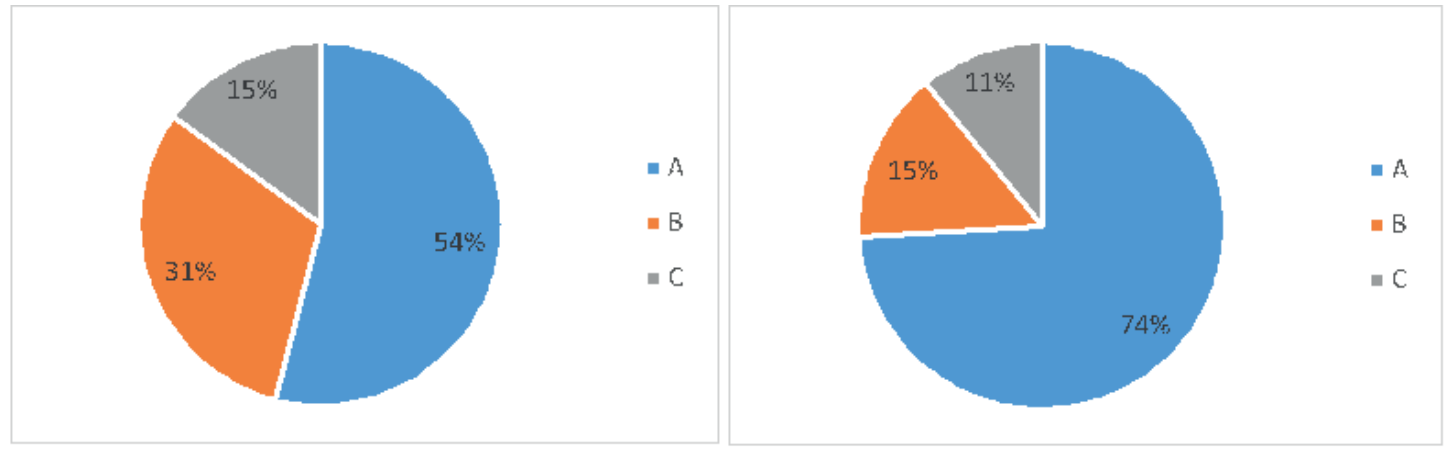

Question number 10 highlights the students' feeling of empathy towards children with SEN. Analyzing the answers of the students from the 2 cycles of education, we came to the conclusion that there are students who would prefer to work separately from children with SEN. We found this by reading the answers in point D, where $10 \%$ of secondary school students do not empathize with students with SEN, and $11 \%$ of primary school believe that they are not sufficiently developed physically and intellectually and cannot understand the physical education class. The other percentages are as follows: $34 \%$ would call them in their own team; 33\% would encourage them when they could not manage; $23 \%$ comforted them when others laughed at them. These are the statements of secondary school students. The students from the primary cycle chose the following answer variants: $44 \%$ - "I encouraged them, when they can't manage"; $24 \%$ - "I called them in my team"; and $21 \%$ comforted them when others laughed at them.

Related to the inclusion of students with SEN in teams with the other students in the physical education class, $70.40 \%$ of the secondary school students and $71.10 \%$ of the primary school students agree with this approach, and $16.60 \%$ respectively $14.50 \%$ consider that they should be relieved of effort, while $13 \%$ and $14.50 \%$ want to practice separate classes. Both primary and secondary school students (6.5\%) state that the lack of teacher training limits the participation of children with SEN to the physical education lesson. Then the students' opinions on limiting the participation of children with SEN in the physical education lesson are different, and the causes could be the following: $48.2 \%$ of the secondary school students say that it is the children's attitude; $32.3 \%$ say it is the environment; $13 \%$ say that the parents of the children's colleagues are to blame. The students from the primary cycle answered the environment $-56.4 \%$; the children's attitude $-33.9 \%$, and the parents of children's colleagues $-3.2 \%$.

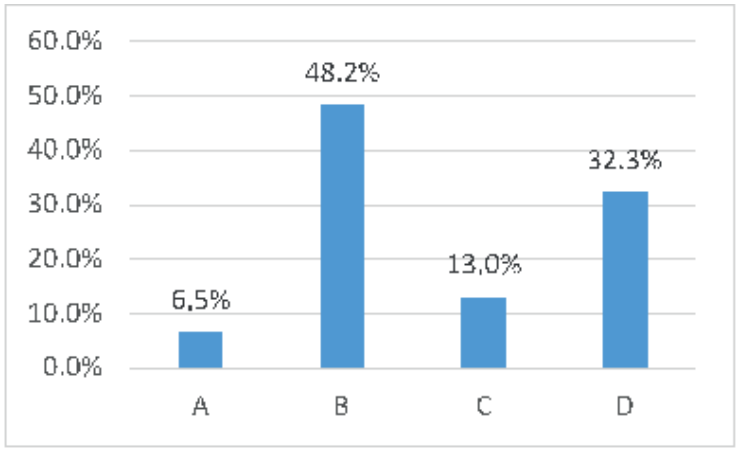

Fig. 7. Secondary school cycle

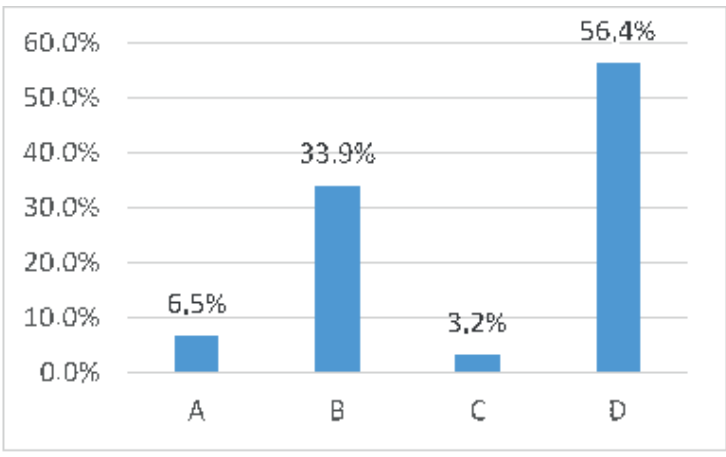

Fig. 8. Primary school cycle

(A - lack of teacher training; B - children's attitude; C - parents of children's colleagues; D - the environment) 
We can notice small differences in percentages between the answers given by primary school students and secondary school students, which shows a certain homogeneity of the two categories of groups, related to the proposed theme. There is also a number between 10$14 \%$ of students who do not accept the presence of students with SEN in physical education classes; therefore, they somewhat refuse to interact with this category of students. Among the determining factors that would impede the inclusion process, we can mention the following: A) lack of specific teacher training, B) children's attitude, C) parents, family, D) environment.

\section{CONCLUSIONS}

Physical education is a component of education, expressed by a type of motor activity that has forms of organization and rules of development, which aims to optimize the biomotor and mental potential of the individual in order to increase the quality of life. Sport is a competitive activity, consisting of all branches of sport, which aims to develop the physical and mental condition of an individual to obtain performance in competitions of all levels, including competitions for people with disabilities.

Physical education and sports develop a complex area of interests, needs, and motivations. It develops ambition, courage, emulation, distributive attention, determination, firmness, perseverance, calm, modesty, honesty, tolerance, multiple traits of will and character. Intellectual qualities, physical qualities and moral qualities are outlined with maximum durability and efficiency in bodily activities, both in people with disabilities and in healthy ones.

Every child has the right to a harmonious education that gives him/them both access to knowledge that will help them know and better understand the world we live in, to develop their potential and autonomous thinking, but also to practice movement and sports, even if it belongs to a disadvantaged category. Children with disabilities also have this right to education, these being included in mainstream education or in special education depending on the severity of the disease. The existence of a child with a disability in a family can also cause additional difficulties for the sibling who does not face such problems. Most likely, the attention of the family members will be focused on the child in difficulty, with the risk of neglecting the sibling's needs. Problems can also arise from the financial point of view, as most of the family's resources are directed towards meeting the needs/ requirements of the child in difficulty. Another category of problems could be caused by the social rejection / isolation of such a family. On the other hand, the brother of a child with disabilities could become responsible and mature sooner.

Sports activity, our culture offers a means (work is another) through which people with disabilities no longer appear to be different. We cannot say that their life will not be improved by this; on the contrary, they will have to get involved in physical and sports activities with a lot of courage. It is also important that the culture of the society that can positively influence the degree of inclusion of students with SEN. In conclusion, we can say that legislative support exists, but the implementation of laws is delayed for financial reasons.

\section{REFERENCES}

[1] Blandul V. Bazele educatiei non-formale. [Basics of non-formal education]. Cluj-Napoca. Editura Mega; 2015. Romanian.

[2] Dragos P, Lucaciu G, Trifa I, Stef Gavris M, Szabo-Alexi P, Buhas S. Aspects regarding the influence of communication on the motivation of employees in some sports organisations. Proceedings of the 4 th international conference of the universitaria consortium (ICU 2018): The impact of sport and physical education science on today society, 73-77. Editografica SRL. INTL Proceedings Div. Bologna, Italy. 2018.

[3] Marcu V, Buhas S. Sport organisations - management and science. Procedia - Social and Behavioral Sciences. 2014;117:678-682. https://doi.org/10.1016/j.sbspro.2014.02.281 
[4] Ilies DC, Buhas R, Ilies M, et al. Sport activities and leisure in nature 2000 protected area - red valley, Romania. J Environ Protect Ecology. 2018;19(1):367-372.

[5] Dragos P, Lucaciu G, Dinis I, Stef Gavris M, Szabo-Alexi P, Buhas S. Conceps concerning the content of childrens training in some sport games Proceedings of the 4 th international conference of the universitaria consortium (ICU 2018): The impact of sport and physical education science on today society, 62 - 72. Editografica SRL, INTL Proceedings Div, Bologna, Italy. 2018.

[6] Ilies DC, Buhas R, Ilies A, Gaceu O, Onet A, Buhas S, Rahota D, Dragos P, Baias S, Marcu F, Onet C. Indoor air qualityissue. Case study: The multipurposesports hall of the University of Oradea. Environmental Engineering \& Management Journal. 2018;17(12):2999-3005. https://doi.org/10.30638/eemj.2018.300

[7] [7] Onet A, Ilies DC, Buhas S, Rahota D, Ilies A, Baias S, Marcu F, Herman GV. Microbial Air Contamination in Indoor Environment of University Sports Hall. Journal of Environmental Protection and Ecology. 2018;19(2):694-703.

[8] Srinivasan SM, Pescatello LS, Bhat AN. Current perspectives on physical activity and exercise recommendations for children and adolescents with autism spectrum disorders. Phys Ther. 2014;94(6):875-89. https://doi.org/10.2522/ ptj.20130157

[9] Cristea D. Integration of disable people through non-formal education activities, scout. Rom J Phys Therapy. 2016;22(37):44-48

[10] Tzuriel D, Hanuka-Levy D. Mother-child and siblings' mediated learning strategies in families with and without children with intellectual disability, Research in developmental disabilities. 2019;95:1-12. https://doi.org/10.1016/j. ridd.2019.103497

[11] Cristea D, Cristea A, Burlau M. Posibilitati de imbunatatire a comportamentului motor la tinerii cu autism. [Possibilities for improving motor behavior of young people with autism]. Rom J Phys Therapy. 2015;21(36):53-61. Romanian.

[12] Buhas S, Herman G, Stef M. Aspects regarding speed developmentin football game in 12-14years old children. GeoSport for Society. 2018;8(1);21-30.

[13] Dragnea A, Mate-Teodorescu S. Teoria sportului. [Sports theory]. Bucharest. Editura FEST; 2002. Romanian.

[14] Government of Romania. National Action Plan in favour of the child. Convention on the Rights of the Child. Decision no. 972/1995, point V. http://legislatie.just.ro/Public/DetaliiDocument/7472

[15] Tripp A, Rizzo T, Webbert L. Inclusion in Physical Education: Changing the Culture. J Phys Educ, Recreation \& Dance. 2007;78(2):32-48. https://doi.org/10.1080/07303084.2007.10597971

[16] Kauffman JM, Hung LY. Special education for intellectual disability: current trends and perspectives. Curr Opin Psychiatry. 2009;22(5):452-6. https://doi.org/10.1097/YCO.0b013e32832eb5c3

[17] Vaz S, Wilson N, Falkmer M, Sim A, Scott M, Cordier R, Falkmer T. Factors associated with primary school teachers attitudes towards the inclusion of students with disabilities. PLoS One. 2015;28;10(8):e0137002. https://doi. org/10.1371/journal.pone.0137002

[18] Avramidis E, Norwich B. Teachers' attitudes towards integration/inclusion: a review of the literature. Eur J Spec Needs Educ. 2002;17(2):129-147. https://doi.org/10.1080/08856250210129056

[19] Ruijs N, Peetsma T, Ineke van der Veen. The presence of several students with special educational needs in inclusive education and the functioning of students with special educational needs. Education Rev. 2010;62(1)1-37. https:// doi.org/10.1080/00131910903469551

[20] Wang L. Perspectives of students with special needs on inclusion in general physical education: a social-relational model of disability. Adapt Phys Activ Q. 2019;36(2):242-263. https://doi.org/10.1123/apaq.2018-0068

[21] Hocutt AM. Effectiveness of special education: is placement the critical factor? Future Child. 1996;6(1):77-102 https://doi.org/10.2307/1602495

[22] Terman DL, Larner MB, Stevenson CS, Behrman RE. Special education for students with disabilities: analysis and recommendations. Future Child. 1996;6(1):4-24. https://doi.org/10.2307/1602491

[23] Haghigh AH, Mohammadtaghipoor F, Hamedinia M, Harati J. Effect of a combined exercise program (aerobi and rebound therapy) with two different ratios on some physical and motor fitness indices in intellectually disabled girl Balt J Health Phys Activ. 2019;11(1):24-33. https://doi.org/10.29359/BJHPA.11.1.03

[24] Sadziak A, Wilinski W, Wieczorek M. Parental burnout as a health determinant in mothers raising disabled children. Balt J Health Phys Activ. 2019;11(3):77-89. https://doi.org/10.29359/BJHPA.11.3.08 